\title{
UTILIZANDO O EDMODO COMO RECURSO TECNOLÓGICO ASSOCIADO À METODOLOGIA TRADICIONAL NO ENSINO DA MATEMÁTICA
}

\author{
M.R. BARBOSA, K.C.M. PEREIRA, K.R. SANTOS* \\ Instituto Federal de Educação, Ciência e Tecnologia do Rio Grande do Norte \\ kleber.santos@ifrn.edu.br*
}

Artigo submetido em 27/08/2018 e aceito em 06/01/2019

DOI: 10.15628/holos.2019.7669

\section{RESUMO}

Neste artigo, discorreremos sobre uma pesquisa realizada com o propósito de verificar a eficácia do uso de um Ambiente Virtual de Aprendizagem como recurso tecnológico associado à metodologia tradicional de ensino, na disciplina de matemática. A referida pesquisa ocorreu em uma turma da 1 a série do ensino médio de uma escola estadual no município de Natal/RN e para sua implementação utilizou-se a rede social educativa EDMODO, visto que essa plataforma reúne características essenciais à realização do trabalho proposto, que consistiu na aplicação de um curso de nivelamento de conteúdos da disciplina de matemática, utilizando as concepções do uso das Tecnologias Digitais da Informação e Comunicação na educação e da Educação a Distância, fazendo uso de materiais como: textos, vídeos, imagens e links para a internet. Os dados coletados na pesquisa apontam como resultados a melhoria na participação dos estudantes nas atividades escolares e, por conseguinte, no desempenho na realização das avaliações.

PALAVRAS-CHAVE: Ambiente Virtual de Aprendizagem, Tecnologias Digitais da Informação e Comunicação, Educação a Distância.

\section{USING EDMODO AS A TECHNOLOGICAL RESOURCE ASSOCIATED WITH TRADITIONAL METHODOLOGY IN MATHEMATICS TEACHING}

\begin{abstract}
In this article, we will discuss a research carried out with the purpose of verifying the effectiveness of the use of a Virtual Learning Environment as a technological resource associated with the traditional teaching methodology in the mathematics. This research was carried out in a class 1st grade of high school of a state school in the city of Natal/RN and for its implementation the educational social network EDMODO was used, since this platform gathers essential characteristics to the accomplishment of the
\end{abstract}

proposed work, that consisted in the application of a content leveling course of the mathematics, using the concepts of the use of Digital Technologies of Information and Communication in education and Distance Education, making use of materials such as texts, videos, images and links to the Internet. The data collected in the research indicate as results the improvement in students' participation in school activities and, therefore, in the performance of the tests. 


\section{INTRODUÇÃO}

A sociedade contemporânea está completamente habituada a utilização das Novas Tecnologias da Informação e da Comunicação (NTIC) ${ }^{1}$,seja em transações bancárias, nas empresas, nos negócios, no lazer ou simplesmente para se comunicar. Isso porque, segundo Valente (1999), as NTIC não só se encontram presentes em todos os segmentos da sociedade como tem mudado suas práticas e hábitos.

Ainda segundo Valente (1999, p.32), “A educação é um serviço e, como tal, sofre e se adequa às concepções paradigmáticas que vive a sociedade. Portanto, ela passa pelas mesmas transformações que outros segmentos da sociedade passam". Neste sentido, a educação começa a seguir essa tendência através do uso das tecnologias digitais, permitindo que os alunos deixem de ser meros receptores de informação e passem a ser participantes ativos do seu aprendizado, isso implica ser capaz de saber pensar, criar, aprender a aprender, tomar decisões e buscar soluções para resoluções de problemas, enquanto permite que o papel do professor deixe de ser o de simples entregador de informação para ser o de colaborador, facilitador, supervisor e consultor do aluno nesta nova concepção de construção do conhecimento (VALENTE, 1999).

Nesse sentido, buscamos uma forma de agregar a utilização das tecnologias digitais às metodologias utilizadas em sala de aula de modo a proporcionar uma forma diferenciada, atual e significativa na construção do conhecimento dos estudantes da Educação Básica.

Dessa forma, a pesquisa aqui delimitada implementou uma ação pedagógica, cujo recurso principal é um Ambiente Virtual de Aprendizagem (AVA) que possibilita aos estudantes uma nova ideia de "espaço escolar".

Esta pesquisa tem o propósito de avaliar o desempenho dos alunos na utilização de uma plataforma de ensino online, bem como minimizar as possíveis carências de aprendizado na disciplina de matemática, verificando ainda as possibilidades pedagógicas desse ambiente virtual, com vistas a sua utilização em outras disciplinas.

O AVA escolhido para a realização deste trabalho foi o Edmodo e nossa escolha para utilização dessa plataforma se deve ao fato de ela reunir características que julgamos essenciais para obtenção de resultados satisfatórios no desenvolvimento dessa pesquisa. Tais características, deve-se ao fato de o Edmodo ser uma rede social educativa utilizada na internet, sem pagamento de licença para uso, que inclui ferramentas básicas para um fluxo de interação, permitindo a postagem de documentos de texto, vídeos e imagens. Possibilita ainda a criação de tarefas e questionários objetivos e subjetivos, com diferentes tipos de questões. Possui também, uma agenda de tarefas que permite ao professor programar as atividades, e aos alunos, verificar as datas limites para entrega dessas. Outra possibilidade, não menos importante, é a de os pais ou responsáveis poderem se cadastrar na plataforma e acompanhar, de modo passivo, o progresso dos filhos. Além disso, a rede social Edmodo pode ser facilmente acessada por meio de seu aplicativo para dispositivos móveis.

\footnotetext{
${ }^{1}$ Tecnologias digitais cuja utilização está associada basicamente ao uso de um software, de um hardware e da internet (VALENTE, 1999).
} 
Para utilização do referido AVA, planejamos um curso de nivelamento para estudantes de uma turma da primeira série do ensino médio, onde seriam abordados os seguintes conteúdos: conceito de equações, equações do 1ㅇ grau e resolução de problemas do 1ㅇg grau, considerando que esses tópicos são de grande importância para o desenvolvimento na aprendizagem de conteúdos da Matemática do ensino médio, bem como de diversos assuntos de disciplinas afins, visto que, parte significativa dos estudantes que iniciam esse nível de ensino não possuem o conhecimento necessário desse conteúdo.

\section{AS TECNOLOGIAS DA INFORMAÇÃO E COMUNICAÇÃO E SUAS CONTRIBUIÇÕES PARA A EDUCAÇÃO}

Observando atentamente o comportamento da sociedade atual, percebemos que o desenvolvimento tecnológico que vem ocorrendo nos últimos anos, tem permitido aos variados segmentos sociais a utilização das TICs nos diversos contextos do cotidiano. Essa popularização do emprego das TICs, deve- se, em parte, às facilidades proporcionadas por esse recurso na realização de diversas tarefas habituais, na ampliação do conhecimento e, dentre outros fatores, na ampliação de meios para a comunicação.

Frente a essa realidade e sendo a educação um segmento que não se pode dissociar do contexto social, faz-se necessário o uso das TIC em suas atividades, quer sejam de gestão quer sejam pedagógicas, sendo essas últimas, o objeto de interesse de nossa pesquisa, visto que, segundo Almeida e Valente $(2011$, p.6) "as tecnologias fazem parte de nossas vidas, influenciam o processo de estruturação do nosso pensamento e, em especial, o modo de ser, agir e pensar das gerações que hoje frequentam nossas salas de aula."

Ainda segundo esses autores, "as TIC podem ser extremamente úteis como ferramentas cognitivas, desempenhando diferentes papéis, auxiliando tanto o aluno quanto o professor". (ALMEIDA E VALENTE, 2011,p.73).

Nesse sentido, entendemos as novas tecnologias como valorosos recursos, os quais podemos utilizar, com fins pedagógicos, no processo de construção do conhecimento, o que nos remete, mais uma vez, ao pensamento de Borba (2002) que considera o fato de que na história da humanidade sempre houve uma tecnologia associada à construção dos saberes.

Concordando com o raciocínio desse autor, nossa pesquisa procurou observar a melhor forma de utilizar as TICs, em favor da aprendizagem, mediando o processo de construção do conhecimento com o uso de um AVA. Durante o percurso do estudo, dialogamos com autores como Almeida, Valente e outros estudiosos que tratam da utilização das TICs como recursos a serem utilizados em sala de aula e buscamos nas concepções da E-learning ${ }^{2}$, respaldo para o desenvolvimento de um trabalho que possa dinamizar as práticas educacionais existentes. A esse respeito, alertam Pantoja e Zwierewicz (2007, p. 172) “cabe à educação tradicional dinamizar-se

${ }^{2}$ Modalidade de ensino caracterizada pela mobilidade, onde, o aprendizado acontece mesmo quando alunos e professores encontram-se em espaço e tempo diferentes. Para que isso seja possível se faz necessário a utilização de um Ambiente Virtual de Aprendizagem (CAÇÃO; DIAS, 2003). 
pela educação digital e imprimir um novo ritmo ao processo educativo, o ritmo do aprender a aprender continuamente em espaços diferenciados."

Vale salientar também que:

A E-learning é normalmente sinónimo de «aprendizagem electrónica» ou «formação a distância via Internet». É um tipo de aprendizagem na qual a informação e o material de estudo se encontram disponíveis na Internet. Para aceder a esse material (aulas, documentos de apoio, testes, etc.), é necessário um computador (ou outro equipamento com funções similares, por exemplo, um PDA), ligação à Internet e software de navegação na Web. O e-learning caracteriza-se pela mobilidade do ensino, podendo o aluno e o tutor ou formador estarem separados por milhares de quilómetros. $\mathrm{O}$ aluno poderá aceder às aulas onde quer que esteja - desde que exista ligação à Internet sem necessidade de estar presente numa sala de aula. Com o e-learning é também possível aceder à formação a qualquer momento, sem necessidade de cumprir um horário rígido, uma vez que as aulas estão permanentemente disponíveis na Internet, 24 horas por dia. (CAÇÃO; DIAS, 2003, p.24).

Isto posto, entendemos estar diante de um novo modelo de aprendizagem em que o estudante passa a ser o principal responsável pela construção do seu conhecimento e ao professor cabe auxiliá-lo nessa tarefa.

\section{A EQUAÇÃO DO PRIMEIRO GRAU COMO BASE DO CONHECIMENTO MATEMÁTICO PRÁTICO}

O uso das equações está intimamente ligado à resolução de questões práticas do dia a dia. É por meio das equações que traduzimos diversos problemas para a linguagem matemática a fim de resolvê-los de maneira prática e organizada. Contudo, o uso de equações para resolver problemas do cotidiano não é algo novo, duas das principais fontes de informações sobre a matemática egípcia antiga, o papiro de Moscou (aproximadamente 1850 a.C.) e o papiro de Rhind (aproximadamente 1650 a.C.), registram juntos 110 problemas ligados a atividades do cotidiano, como por exemplo, o quão substanciosos eram o pão e a cerveja, questões sobre o balanceamento de rações para animais e ainda acerca do armazenamento de grãos. Em muitos desses problemas a resolução recaia em uma equação linear simples (EVES, 2004).

Assim, por ser largamente aplicável, o estudo das equações se constitui uma ferramenta essencial na percepção do mundo e na construção do pensamento matemático. A esse respeito, Stewart afirma:

Equações são a seiva vital da matemática, da ciência e da tecnologia. Sem elas nosso mundo não existiria na forma atual [...]. Quero convencer você de que as equações têm um papel fundamental na criação do mundo de hoje, desde a cartografia até a navegação por satélite, da música à televisão, da descoberta da América à exploração das luas de Júpiter. Felizmente, você não precisa ser um gênio para apreciar a beleza e a poesia de uma boa e significativa equação. (STEWART, 2013, p.7). 
Além disso, Garbi (2010, p.1) afirma que: "as equações - algébricas, exponenciais, diferenciais, trigonométricas ou de qualquer outra natureza - constituem, pelo menos do ponto de vista prático, a parte mais importante da Matemática."

Esse autor é enfático ao afirmar ainda que, "Qualquer problema que possa ser solucionado através dos números certamente será tratado, direta ou indiretamente, por meio de equações." (GARBI, 2010, p.1).

Para que haja melhor compressão e habilidade no manuseio das equações, é necessário que seu estudo adquira sentido e se torne agradável ao estudante. Para tanto, é preciso que o seu conhecimento parta de situações simples, a exemplos dos problemas que originam equações de primeiro grau. Esse tipo constitui o primeiro formato de equação que aprendemos na escola visto que os livros didáticos brasileiros para a disciplina de matemática apresentam os primeiros ensaios de resolução de problemas e equações do primeiro grau nas séries iniciais do ensino fundamental. Dessa forma, os conhecimentos adquiridos com o estudo do conteúdo de equações do primeiro grau servirão de base em diversas situações reais e serão utilizados para a compreensão e resolução de outros temas matemáticos como as funções afim, as equações de retas, os sistemas lineares, dentre outros.

Além disso, uma boa compreensão dos estudos das equações do primeiro grau facilita o entendimento de conteúdos de outras áreas do conhecimento como a física e a química.

Nesse contexto, dada a larga aplicabilidade desse conteúdo, adquirir domínio no seu manuseio e na sua resolução, representa o reconhecimento dessa ferramenta essencial para o avanço escolar e para a compreensão do mundo que nos cerca.

\section{METODOLOGIA}

De acordo com os métodos utilizados, nossa pesquisa caracterizou-se como uma PesquisaAção já que "procura diagnosticar um problema específico numa situação específica, com vistas a alcançar algum resultado prático". (GIL, 2010, p.42). Além disso, utilizamos a observação participante como método de coleta de dados, visto que esses dados foram obtidos durante a aplicação do projeto, ou seja, houve interação do pesquisador com o fenômeno estudado (MAIA; OLIVEIRA, 2006).

Para que pudéssemos desenvolver o trabalho, inicialmente, mantivemos contato com algumas escolas da rede estadual do Rio Grande do Norte localizadas nos municípios de Natal e Parnamirim, a fim de verificarmos a viabilidade da implantação dessa pesquisa, uma vez que se dependia de fatores como: a existência de um laboratório de informática com computadores em funcionamento e acesso internet. A escola escolhida dentre as contatadas foi a Escola Estadual Professora Josefa Sampaio, localizada no município de Natal/RN e a pesquisa aconteceu em uma turma da 1a série do Ensino Médio da referida escola. Essa turma apresentava um total de 21 alunos dos quais cinco apresentam algum tipo de necessidade especial comprovada por meio de laudos emitidos por especialistas das áreas na qual recebem acompanhamento. As necessidades apresentadas por esses estudantes são: discalculia, esquizofrenia, autismo, transtorno bipolar e transtorno de déficit de atenção. 
Definidos a escola, a turma, o AVA e os conteúdos a serem trabalhados, iniciamos a implementação dos procedimentos didáticos que julgamos essenciais a condução da pesquisa. Inicialmente, foram programados encontros presenciais semanais que tiveram o propósito de habilitar os estudantes e demais envolvidos, quanto ao uso do referido AVA e de suas funcionalidades. Posteriormente, esses encontros presenciais foram utilizados como forma de suporte para sanar dúvidas dos estudantes em relação aos conteúdos, superar possíveis dificuldades no uso do AVA e receber feedback em relação a implementação da ferramenta Edmodo. Para melhor compreensão do leitor, discorreremos sobre as etapas do percurso metodológico realizado na condução de tais procedimentos.

1a Etapa - Verificação do nível de conhecimento dos alunos.

Inicialmente, fomos apresentados a turma pela professora de matemática (que nos acompanhou durante toda a pesquisa em sala de aula). Em seguida apresentamos, de forma didática, o ambiente Edmodo e suas funcionalidades e explicamos o projeto hora iniciado. $\mathrm{Na}$ sequência iniciamos o cadastramento dos alunos na referida plataforma.

Ainda na 1a etapa, porém no segundo encontro, realizamos a aplicação de um questionário sociocultural com o propósito de responder a questões como: período de tempo diário dedicados aos estudos, tipos de materiais usados nesses momentos, utilização de dispositivos móveis ou computadores com acesso à internet em momentos de estudo fora do ambiente escolar e o tempo utilizado com aplicativos de internet para o lazer ou outro propósito que não fosse estudar.

Os aspectos verificados no questionário geraram dados quantitativos que se encontram detalhados nas Tabelas a seguir:

- Perfil Pessoal do Estudante (sexo e idade)

Tabela 1: Perfil pessoal do estudante.

\begin{tabular}{l|c|c}
\hline \multicolumn{1}{c|}{ Sexo } & № de alunos & $(\%)$ \\
\hline Masculino & 13 & $61,9 \%$ \\
Feminino & 8 & $38,1 \%$ \\
\hline Total & 21 & $100 \%$ \\
\hline Idade & № de alunos & $(\%)$ \\
\hline Menos de 15 & 3 & $14,3 \%$ \\
Entre 15 e 17 & 13 & $61,9 \%$ \\
Entre 18 e 20 & 4 & $19,0 \%$ \\
Mais de 20 & 1 & $4,8 \%$ \\
\hline Total & 21 & $100 \%$ \\
\hline
\end{tabular}

Fonte: Autor.

- Perfil Sociocultural do Estudante (possui acesso à internet, locais onde acessa a internet e dispositivos utilizados para o acesso à internet) 
Tabela 2: Perfil socioeconômico do estudante.

\begin{tabular}{|c|c|c|}
\hline Possui acesso à Internet & № de alunos & $(\%)$ \\
\hline Sim & 18 & $85,7 \%$ \\
\hline Não & 3 & $14,3 \%$ \\
\hline Total & 21 & $100 \%$ \\
\hline \multicolumn{3}{|c|}{ Locais onde acessa a internet } \\
\hline Local & № de alunos & $(\%)$ \\
\hline Em casa & 7 & $33,3 \%$ \\
\hline Casa de amigos & 5 & $23,8 \%$ \\
\hline Casa de pessoas da família & 6 & $28,6 \%$ \\
\hline Escola & 2 & $9,5 \%$ \\
\hline Outros & 1 & $4,8 \%$ \\
\hline Total & 21 & $100 \%$ \\
\hline \multicolumn{3}{|c|}{ Possui algum dos itens } \\
\hline Item & № de alunos & $(\%)$ \\
\hline Tablet & 2 & $11,1 \%$ \\
\hline Smartphone & 16 & $88,9 \%$ \\
\hline Total & 18 & $100 \%$ \\
\hline \multicolumn{3}{|c|}{ Itens existentes em casa } \\
\hline Item & № de alunos & $(\%)$ \\
\hline Computador & 5 & $27,8 \%$ \\
\hline Notebook & 7 & $38,9 \%$ \\
\hline TV com acesso à Internet & 6 & $33,3 \%$ \\
\hline Total & 18 & $100 \%$ \\
\hline
\end{tabular}

Fonte: Autor.

- Utilização do Tempo (Horas por dia utilizadas vendo tv, Horas por dia utilizando a internet como diversão, Horas por dia utilizadas com estudos fora da sala de aula, Tipo de material utilizado para estudar fora da sala de aula).

Tabela 3: Utilização do tempo.

\begin{tabular}{|c|c|c|}
\hline \multicolumn{3}{|c|}{ Horas por dia utilizadas vendo tv } \\
\hline № de horas & № de alunos & $(\%)$ \\
\hline De 1 a 2 horas & 11 & $52,4 \%$ \\
\hline De 2 a 4 Horas & 1 & $4,8 \%$ \\
\hline Mais de 4 horas & 9 & $42,8 \%$ \\
\hline Total & 21 & $100 \%$ \\
\hline \multicolumn{3}{|c|}{ Horas por dia, utilizando a internet como diversão } \\
\hline № de horas & № de alunos & (\%) \\
\hline De 1 a 2 horas & 3 & $16,7 \%$ \\
\hline De 2 a 4 Horas & 5 & $27,8 \%$ \\
\hline Mais de 4 horas & 10 & $55,5 \%$ \\
\hline Total & 18 & $100 \%$ \\
\hline
\end{tabular}

Horas por dia, utilizadas com estudos fora da sala de aula 


\begin{tabular}{l|c|c}
\hline \multicolumn{1}{c|}{ № de horas } & № de alunos & (\%) \\
\hline 1 hora & 9 & $42,9 \%$ \\
2 horas & 4 & $19,0 \%$ \\
3 horas & 2 & $9,5 \%$ \\
Não estuda fora da sala de aula & 6 & $28,6 \%$ \\
\hline Total & 21 & $100 \%$ \\
\hline
\end{tabular}

Tipo de material utilizado para estudar fora da sala de aula

\begin{tabular}{l|c|c}
\hline \multicolumn{1}{c|}{ Material } & № de alunos & (\%) \\
\hline Livros didáticos & 8 & $40,0 \%$ \\
Apostilas & 1 & $5,0 \%$ \\
Internet & 11 & $55,0 \%$ \\
\hline Total & 20 & $100 \%$ \\
\hline
\end{tabular}

Fonte: Autor.

- Utilização de plataformas educativas (conhece a plataforma educativa Edmodo, conhece outra plataforma educativa)

Tabela 4: Utilização de plataformas educativas.

\begin{tabular}{|c|c|c|}
\hline \multicolumn{3}{|c|}{ Quanto a plataforma educativa Edmodo, você: } \\
\hline Situação & № de alunos & $(\%)$ \\
\hline Conhece e utiliza para estudar & 1 & $4,8 \%$ \\
\hline Conhece, mas não utiliza & 2 & $9,5 \%$ \\
\hline Não conhece & 18 & $85,7 \%$ \\
\hline Total & 21 & $100 \%$ \\
\hline \multicolumn{3}{|c|}{ Quanto a outras plataformas educativas, você: } \\
\hline Situação & № de alunos & $(\%)$ \\
\hline Conhece e utiliza para estudar & 3 & $14,2 \%$ \\
\hline Conhece, mas não utiliza & 1 & $4,8 \%$ \\
\hline Não conhece & 17 & $81,0 \%$ \\
\hline Total & 21 & $100 \%$ \\
\hline
\end{tabular}

Ainda nessa etapa, aplicamos um teste de sondagem com o propósito de verificar o nível de conhecimento dos estudantes nos assuntos escolhidos, a fim de nortear a abordagem dos conteúdos do curso de nivelamento no ambiente virtual. O conteúdo e o resultado desse teste estão descritos a seguir:

Equação e problemas do 10 grau.

Questão 1 - Encontre as raízes das seguintes equações do primeiro grau:
a) $7 x+5=19$
b) $6+3 x=42$
c) $5 x-8=3 x+6$

Questão 2 - Resolva os seguintes problemas relacionados a equação do primeiro grau:

a) Adivinhe o número que eu pensei. 
“Pensei em um número, subtraí 3 unidades, multipliquei o resultado por 5 . 0 resultado final foi 65 , em que numero eu pensei?"

b) Em um quadrado mágico, a soma dos três números de cada linha, coluna ou diagonal sempre dá o mesmo resultado. Com base nessa informação, preencha o quadrado mágico abaixo.

Figura 1: Quadrado mágico.

\begin{tabular}{|c|c|c|}
\hline $\mathrm{x}$ & 17 & \\
\hline & $\mathrm{x}+1$ & \\
\hline & $\mathrm{x}-3$ & $\mathrm{x}+2$ \\
\hline
\end{tabular}

Fonte: Autor.

Tabela 5: Resultado do teste de sondagem - questão 1, letra a.

\begin{tabular}{l|c|c}
\hline \multicolumn{1}{c|}{ Situação } & № de Alunos & $(\%)$ \\
\hline Acertou & 9 & $42,9 \%$ \\
Errou & 2 & $9,5 \%$ \\
Não fez & 10 & $47,6 \%$ \\
\hline Total & 21 & $100,0 \%$ \\
\hline
\end{tabular}

Fonte: Autor.

Tabela 6: Resultado do teste de sondagem - questão 1, letra b.

\begin{tabular}{l|c|c}
\hline Situação & № de Alunos & $(\%)$ \\
\hline Acertou & 8 & $38,1 \%$ \\
Errou & 2 & $9,5 \%$ \\
Não fez & 11 & $52,4 \%$ \\
\hline Total & 21 & $100,0 \%$ \\
\hline
\end{tabular}

Fonte: Autor.

Tabela 7: Resultado do teste de sondagem - questão 1, letra c.

\begin{tabular}{l|c|c}
\hline \multicolumn{1}{c|}{ Situação } & № de Alunos & $(\%)$ \\
\hline Acertos & 7 & $33,3 \%$ \\
Erros & 2 & $9,5 \%$ \\
Não fez & 12 & $57,2 \%$ \\
\hline Em branco & 21 & $100,0 \%$ \\
\hline
\end{tabular}

Fonte: Autor.

Tabela 8: Resultado do teste de sondagem - questão 2, letra a.

\begin{tabular}{l|c|c}
\hline \multicolumn{1}{c|}{ Situação } & № de Alunos & $(\%)$ \\
\hline Acertos & 0 & $0 \%$ \\
Erros & 5 & $24 \%$ \\
Em branco & 16 & $76 \%$ \\
\hline Total & 21 & $100,0 \%$ \\
\hline
\end{tabular}

Fonte: Autor. 
Tabela 9: Resultado do teste de sondagem - questão 2, letra b.

\begin{tabular}{l|c|c}
\hline Situação & No de Alunos & (\%) \\
\hline Acertos & 0 & $0 \%$ \\
Erros & 1 & $4,8 \%$ \\
Em branco & 20 & $95,2 \%$ \\
\hline Total & 21 & $100 \%$ \\
\hline
\end{tabular}

Fonte: Autor.

2a Etapa - Utilizando o Edmodo

Após a aplicação do teste de sondagem e da verificação dos resultados, iniciamos o curso de nivelamento no AVA. As revisões na plataforma aconteceram a partir de postagens dos conteúdos em forma de textos, vídeos, imagens e links. Inicialmente elaboramos uma aula sobre o conceito e estrutura de equação e equação do primeiro grau e disponibilizamos o conteúdo em um arquivo pdf. Em seguida, para verificação da aprendizagem, propomos a realização de uma atividade onde os estudantes demonstravam os conhecimentos adquiridos, por meio de comentários, a partir da observação de imagens utilizadas na forma de pôster.

Figura 2: Postagem de conteúdo no Edmodo.
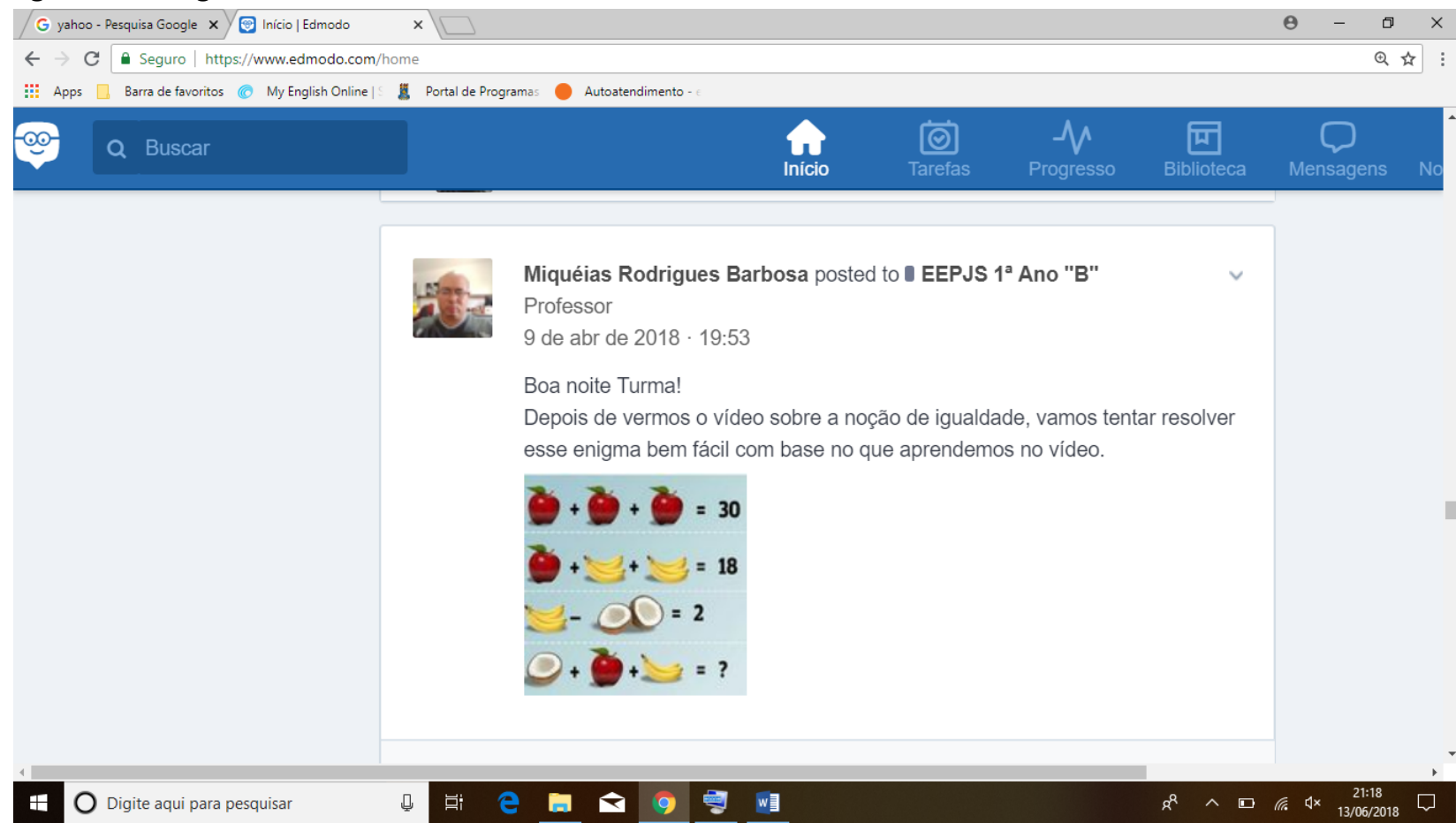

Fonte: Autor.

Dando continuidade ao trabalho, foram inseridas, no ambiente, videoaulas de curta duração para reforçar o aprendizado dos assuntos selecionados para o curso de nivelamento. Em cada postagem ou material disponibilizado, solicitamos aos alunos que postassem suas dúvidas ou fizessem comentários pertinentes para que pudéssemos acompanhar o aprendizado na plataforma. Ainda para verificar a aprendizagem, elaboramos tarefas e testes no próprio Edmodo onde os estudantes puderam resolver questões do tipo múltipla escolha, resposta curta, 
completar lacuna e verdadeiro ou falso. Na elaboração dessas tarefas, foram programadas a correção automática bem como a pontuação referente a cada questão e a pontuação recebida pelo aluno, conforme o número de acertos.

No assunto seguinte (problemas com equação do primeiro grau) utilizamos o mesmo procedimento, acrescentando uma outra ferramenta com o propósito de dinamizar o aprendizado. Criamos uma história em quadrinhos utilizando um programa disponibilizado na internet e a partir disso, idealizamos uma atividade na plataforma onde os alunos realizaram a tarefa com base na leitura dos quadrinhos.

Figura 3: Quadrinhos utilizados para tornar o aprendizado mais interessante.

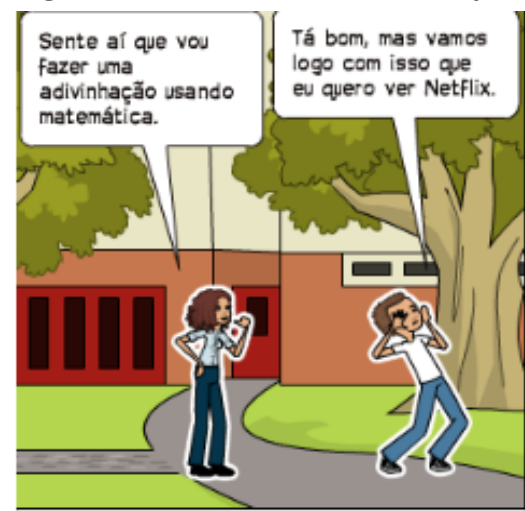

Ela o convence a participar da brincadeira que the chamou a atenção na aula sobre equaçôes.

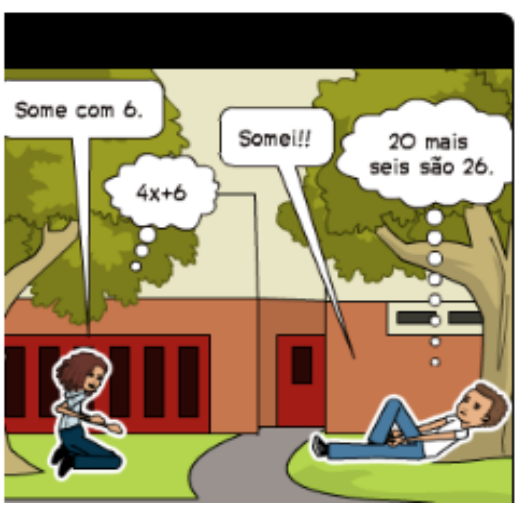

Fonte: Autor.

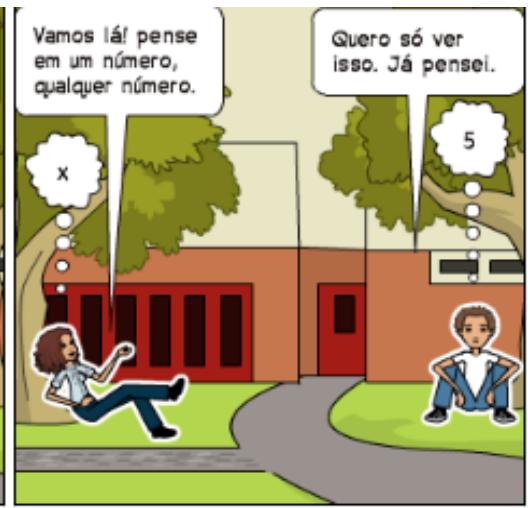

Rebeca começa sugerindo que Anderson pense em um número qualquer...

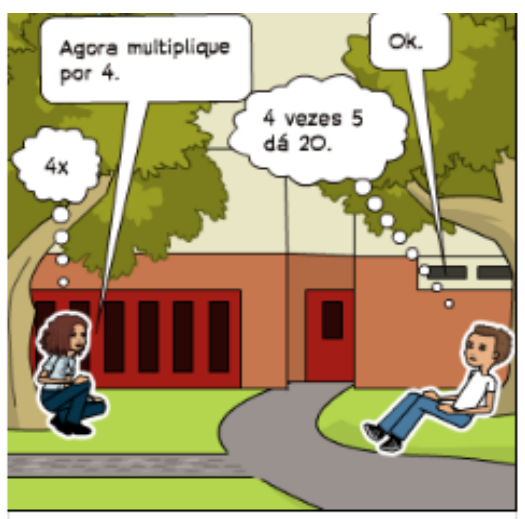

...e ele começa a realizar os cálculos.
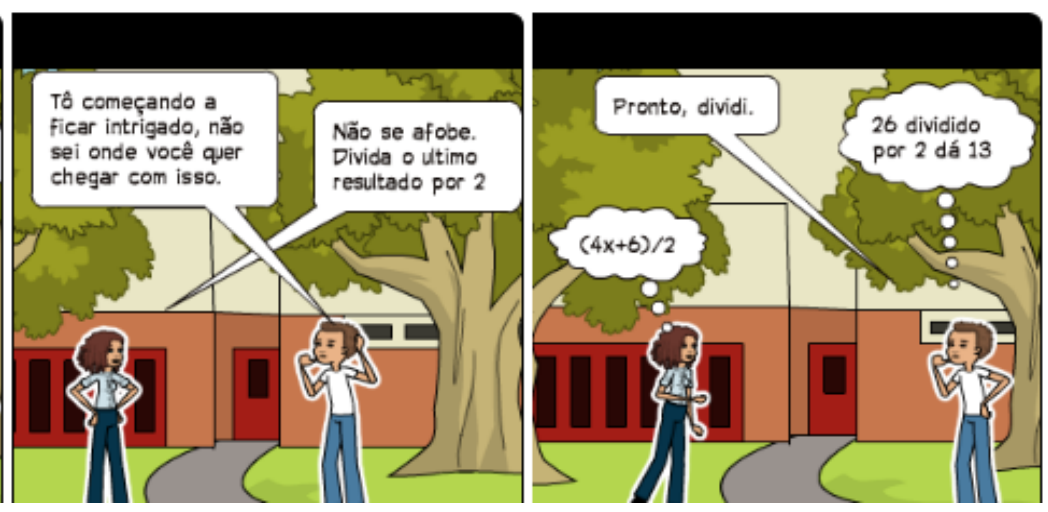

https://www.pixton.com/br/storyboard/IOnzwhq5

3a Etapa - Avaliação da aprendizagem no Edmodo.

Após a segunda etapa, aplicamos uma prova escrita com o propósito de verificar a aprendizagem dos conteúdos revisados na plataforma Edmodo. Essa avaliação constava de dez questões em que foram aferidos os conhecimentos dos alunos acerca do conceito e estrutura de uma equação, da capacidade de identificar uma equação do primeiro grau entre outros tipos de equações, conceituar e reconhecer a incógnita de uma equação, bem como seus membros e termos e, por fim, resolver equações do primeiro grau e problemas cujas resoluções recaiam nesse 
tipo de equação. A avaliação continha questões dos tipos verdadeiro ou falso, múltipla escolha, relacionar colunas, completar lacunas, resolver equações e interpretar e resolver problemas.

Por ocasião da realização da avaliação, dos vinte e um alunos da turma, somente dezessete estavam presentes e realizaram a prova. Cabe ressaltar que durante a aprendizagem no Edmodo, um total de oito alunos não tiveram participação ativa na plataforma e destes, seis são os que responderam no questionário sociocultural que não estudavam fora da sala de aula.

Para melhor compreensão do leitor acerca da participação dos alunos nas atividades durante a pesquisa, elaboramos o seguinte esquema no qual, separamos os estudantes com necessidade especiais por entendermos que tal condição interferia de alguma forma no aprendizado.

Figura 4: Distribuição da participação dos alunos nas atividades

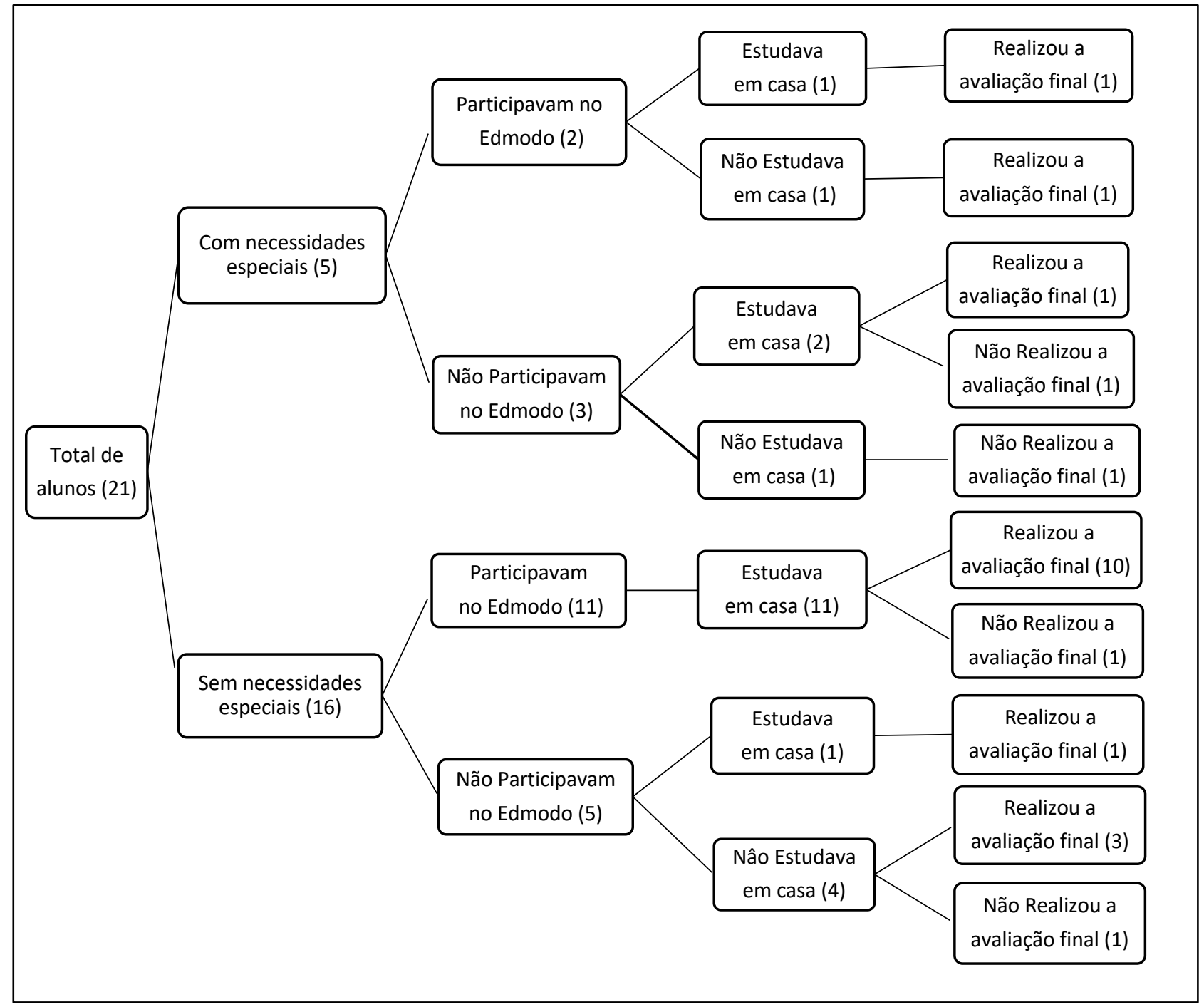

Fonte: Autor.

Os resultados da avaliação final estão tabulados a seguir. 
Tabela 10: Resultado da prova final.

\begin{tabular}{l|c|c|l|l}
\hline \multicolumn{1}{c|}{ Habilidade } & Acertou & Errou & Não fez & \multicolumn{1}{c}{ Total } \\
\hline Conceito de equação & $15(88 \%)$ & $2(12 \%)$ & $0(0 \%)$ & 17 Alunos \\
Grau de uma equação & $13(76 \%)$ & $4(24 \%)$ & $0(0 \%)$ & 17 Alunos \\
Estrutura de uma equação & $12(71 \%)$ & $5(29 \%)$ & $0(0 \%)$ & 17 Alunos \\
Reconhecer incógnita & $12(71 \%)$ & $5(29 \%)$ & $0(0 \%)$ & 17 Alunos \\
Resolver equações do 10 grau & $9(53 \%)$ & $2(12 \%)$ & $6(35 \%)$ & 17 Alunos \\
Resolver problemas do 10 grau & $9(53 \%)$ & $3(18 \%)$ & $5(29 \%)$ & 17 Alunos \\
\hline
\end{tabular}

Fonte: Autor.

\section{RESULTADOS E DISCUSSÕES}

Os resultados da prova final, constantes na tabela 10, mostram que: $88 \%$ dos alunos compreenderam o conceito de equação, $76 \%$ conseguiram identificar o grau de uma equação e 71\% obtiveram êxito no reconhecimento da incógnita e da estrutura de uma equação. Percebemos ainda que, em se tratando de resolver equações e problemas do primeiro grau, $53 \%$ dos alunos acertaram as questões propostas nos dois tipos de abordagem. Sobre esses dois últimos aspectos, os principais a serem analisados, visto que suas resoluções foram objetos de observação do teste de sondagem, pudemos verificar que o percentual de alunos que resolveram corretamente as equações passou de uma média de $38,1 \%$ para $53 \%$. Com relação a resolução correta dos problemas do primeiro grau constantes no teste de sondagem, não se observou acerto por parte dos alunos, já na prova final $53 \%$ dos estudantes presentes acertaram esse tipo de questão.

No tocante aos estudantes que erraram algum tipo de questão na prova final, percebe-se que seu percentual sofreu um aumento em relação ao teste de sondagem, visto que a menor porcentagem de alunos que erraram a questão cujo resultado encontra-se na tabela 9 no teste de sondagem $(4,8 \%)$, contrasta com a menor porcentagem de alunos que erraram questões da prova final, que corresponde a $12 \%$ (tabela 10). Quanto ao maior percentual de estudantes que erraram na resolução de questões do teste de sondagem, esse, corresponde a $24 \%$ (tabela 8) enquanto que na prova final, a maior representatividade de estudantes que erraram questões corresponde a $29 \%$.

Apesar do exposto, uma análise mais detalhada dos dados mostra que o crescimento do percentual de erros sofreu influência do número de estudantes que responderam questões, visto que a falta de resposta a determinada questão não é contabilizada como erro ou acerto. No teste de sondagem podemos observar elevado número de abstenções na resolução das questões, enquanto que na realização da prova final essa característica sofreu forte redução, o que nos aponta que houve maior empenho dos estudantes na aplicação dos conhecimentos adquiridos a partir dos conteúdos abordados no decorrer do curso. Essa tentativa de resolução provocou maior índice de acertos e consequentemente de erros em relação aos resultados observados no teste de sondagem.

É relevante mencionarmos que os percentuais observados nos resultados do teste de sondagem referem-se aos 21 estudantes presentes na ocasião, enquanto que os percentuais 
calculados a partir dos resultados da prova final têm como parâmetro os 17 alunos que a realizaram.

Os resultados apresentados demonstram aumento do empenho por parte dos estudantes na realização das tarefas, bem como avanços no nível de aprendizagem dos conteúdos, uma vez que se percebe, não só o aumento na quantidade de alunos que procuraram resolver as questões, mas, a obtenção de melhores resultados em relação ao desempenho. A isso, somamos o interesse demonstrado por meio da participação nas atividades presenciais, bem como, naquelas que foram desenvolvidas no ambiente virtual. Além dos resultados quantitativos apresentados, salientamos que no período em que realizamos esta pesquisa, a escola não desenvolvia nenhum projeto com o uso de ambientes virtuais e outros recursos tecnológicos com vistas a modernização das práticas pedagógicas o que despertou o interesse de alguns professores na utilização do Edmodo em suas disciplinas, haja vista a motivação apresentada pelos estudantes na realização das atividades. Nesse sentido, observamos que os alunos participantes ativos na plataforma, expressaram satisfação e envolvimento com a metodologia utilizada, o que nos motivou a realizar uma enquete a fim de confirmar a aceitação por parte dos alunos.

Figura 5: Enquete realizada no edmodo.

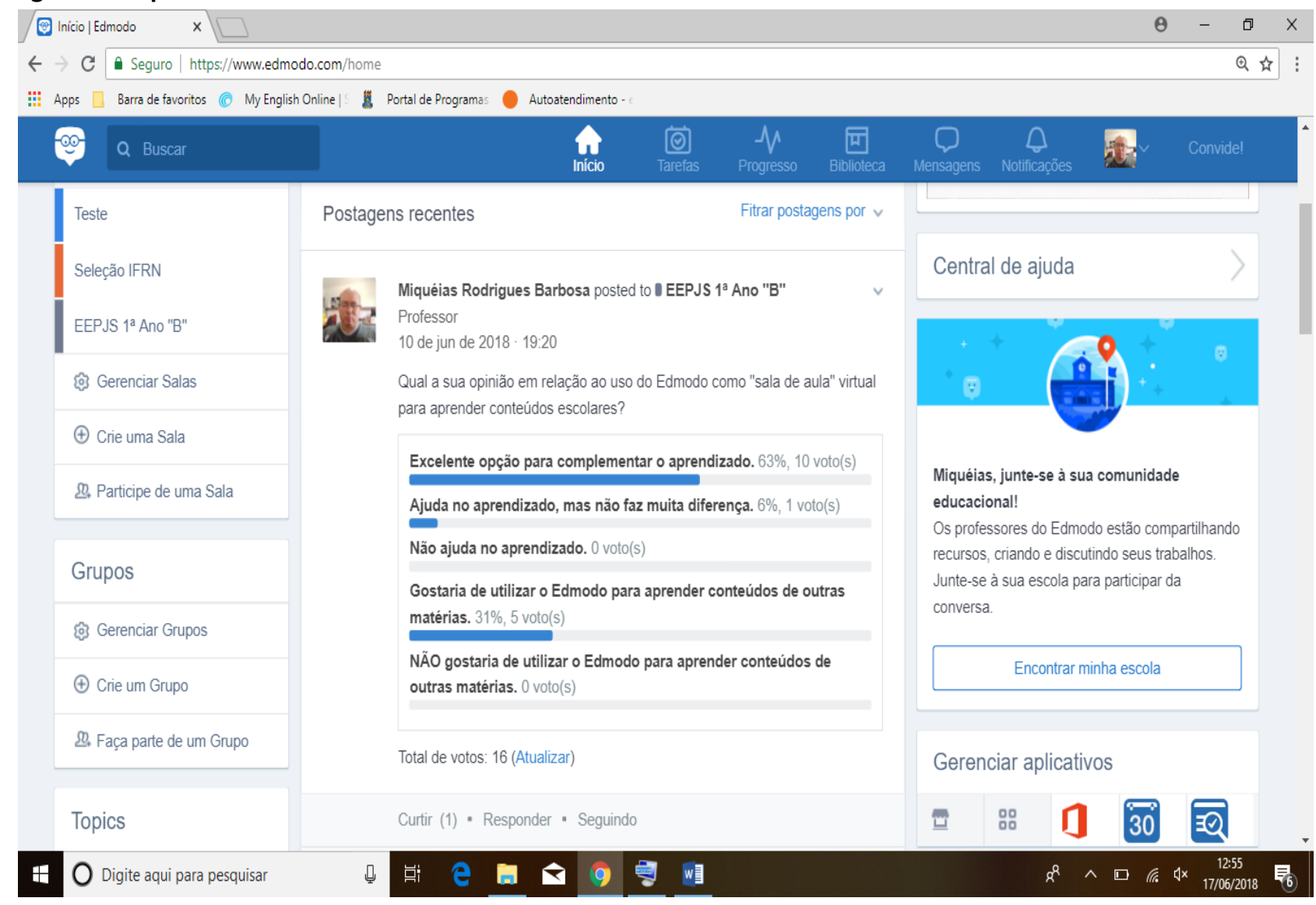

Fonte: www.edmodo.com

Na figura acima, consta o resultado da enquete realizada na própria plataforma onde 16 alunos expressaram suas opiniões acerca do AVA, que obteve um índice de $94 \%$ de aceitação, confirmando a satisfação expressada pelos estudantes em relação ao uso do edmodo. 


\section{CONCLUSÕES}

No tocante a verificação da eficiência do uso do Edmodo como recurso tecnológico no ensino de conteúdos da disciplina de matemática, esta pesquisa aponta novos percursos metodológicos a serem trilhados na busca de resultados quantitativos em termos de participação dos estudantes como seres ativos na construção do seu aprendizado e, em termos qualitativos, na obtenção de melhores resultados desse aprendizado. A eficiência do ambiente virtual Edmodo pode ainda ser experimentada em outras áreas do conhecimento a fim de dinamizar as práticas pedagógicas existentes nas escolas da educação básica com vistas a obtenção de melhoria do aprendizado.

Neste sentido, entendemos que é preciso que cada educador perceba a importância de uma mudança ou pelo menos de agregar uma nova concepção em relação a ensinar, acrescentando aos métodos tradicionais mudanças na metodologia bem como estratégias didáticas diferenciadas onde a relação ensino-aprendizagem possa acontecer de forma não limitada ao espaço físico ou ao tempo. Pantoja e Zwierewicz (2007, p. 172) "cabe à educação tradicional dinamizar-se pela educação digital e imprimir um novo ritmo ao processo educativo, o ritmo do aprender a aprender continuamente em espaços diferenciados".

\section{REFERÊNCIAS BIBLIOGRÁFICAS}

ALMEIDA, M. E. B.; VALENTE, J. A. Tecnologia e currículo: trajetórias convergentes ou divergentes? São Paulo: Paulus,2011.

A melhor maneira para criar quadrinhos. Disponível em: <www.pixton.com> Acesso em: 02 de mar. 2018.

BORBA, Marcelo de Carvalho. Coletivo seres-humanos-com-mídias e a produção do conhecimento matemático. In: I Simpósio Brasileiro de Psicologia da Educação Matemática, 2002, Curitiba. I Simpósio Brasileiro de Psicologia da Educação Matemática. 2001. V. 1. P. 135-146. Disponível em: <http://www.rc.unesp.br/gpimem/downloads/artigos/borba/borba coletivosseres-humanos-com-midias.pdf> Acesso em: 11 jul. 2017.

CAÇÃO, R.; DIAS, P. J. Introdução ao e-learning. 1.ed. Porto: Sociedade Portuguesa de Inovação, 2003. Disponível em: <http://web.spi.pt/madilearning/manual1/IntroducaoaoeLearningformando.pdf >Acesso em: 15 jul. 2017.

Ensine mais. Aprenda mais. Disponível em: <www.edmodo.com> Acesso em: 20 fev. 2018.

EVES, Howard. Introdução à história da matemática. São Paulo: Editora da UNICAMP, 2004.

GARBI, Gilberto G. O romance das equações algébricas. 4.ed. São Paulo: Editora Livraria da Física, 2010.

GIL, A. C. Como elaborar projetos de pesquisa. 5. ed. São Paulo: Atlas, 2010. 
MAIA, L. F.S.; OLIVEIRA, M.V.F. Trabalhos acadêmicos: princípios, normas e técnicas. Natal: Editora do CEFET-RN, 2009.

PANTOJA, A.; ZWIEREWICZ, M. Sociedade da informação, educação digital e inclusão. In: PANTOJA, A.; ZWIEREWICZ, M. (org.) Sociedade da informação, educação digital e inclusão. Florianópolis: Insular, 2007. p. 171-173.

STEWART, Ian. 17 equações que mudaram o mundo. Rio de Janeiro: Zahar, 2013. Disponível em: <http://lelivros.love/book/download-17-equacoes-que-mudaram-o-mundo-ian-stewart-em-epubmobi-e-pdf/> Acesso em: 10 jun. 2018.

VALENTE, J. A. (org.) O computador na sociedade do conhecimento. Campinas: UNICAMP/NIED, 1999. 